\title{
Intellectual Property Policy at The Neuro, an Open Science Institute
}

Dylan Roskams-Edris ${ }^{1}$

1 McGill University

Funding: The first stages of this work were supported by the Tanenbaum Open Science Institute

Potential competing interests: The author is an employee of the Tanenbaum Open Science Institute at The Neuro.

\begin{abstract}
In 2016 The Neuro, otherwise known as the Montreal Neurological Institute and Hospital, became the world's first open science institute. The Neuro's definition of and approach to open science is captured in its Open Science Principles. While most of the goals embedded in the principles have received increasing approval from researchers, funders, and other institutes, The Neuro's stance on intellectual property continues to see resistance. In this paper I describe how The Neuro conceives of the relationship between open science, neuroscience, and intellectual property; how it came to its current policy by examining both broad and Neuro specific innovation trends; and why it believes minimizing academic intellectual property is key to the future of neuroscience research.
\end{abstract}

\section{Definitions}

\author{
Open Access \\ Defined by Budapest Open Access Initiative (BOAl) \\ Novelty Killing Public Disclosure \\ Defined by Dylan Roskams-Edris \\ Proteome \\ Defined by National Cancer Ins titute \\ Metadata \\ Defined by National Cancer Institute \\ Patent Thicket \\ Defined by Carl Shapiro \\ Open Science \\ Defined by Mick Wats on
}




\section{Open Science and Intellectual Property at The Neuro}

When folks from The Neuro talk about open science, no topic is more likely to receive pushback than its stance on intellectual property ("IP"). Data sharing, great, open access publishing, absolutely, sharing code, protocols, and reagents, all for it, not filing for patents or enforcing restrictive IP rights over research outputs, well, wait a minute now.

To bring some clarity to The Neuro's position, and emphasize its importance, I want to explain how The Neuro understands the relationship between neuroscience research, open science, and intellectual property. To do so I beg in by discussing some fundamental concepts and historical examples, move on to an explanation of The Neuro's policy towards IP, and finish by discussing IP-based innovation trends both generally and specific to The Neuro.

\section{The Neuro and The Need for Open Neuroscience}

Two things define The Neuro's institutional identity. One is a commitment to uncovering the mysterious workings of the central nervous system through research; the other is providing world-class clinical care to patients with neurological disorders. These two aspects are, of course, deeply intertwined. Following the vision of The Neuro's founder, the inimitable Wilder Penfield, clinical experience influences research, the insights from which are in turn integrated into the clinic.

As grand as this vision of a feedback loop between neuroscience research and clinical practice was - indeed unique in 1934 when The Neuro was founded - it has become overwhelmingly obvious that, when it comes to understanding the nervous system, it is not enough. With $\sim 86$ billion neurons in the adult human brain ${ }^{[1]}$, each having potentially thousands of dynamic, synaptic connections to its peers (not to mention interacting in largely unknown ways with vast numbers of glial cells), no single institute can possibly generate more than a fraction of the discoveries necessary to understand and treat neurological disorders. In light of this, The Neuro has come to fully embrace the idea that "it takes the world to understand the brain"[2] and that the only way to effectively collaborate on a global scale is to adopt radical sharing through open science.

The need for open science becomes yet more acute when one brings into the equation the current reproducibility (and replicability) crisis plaguing much of the scientific research

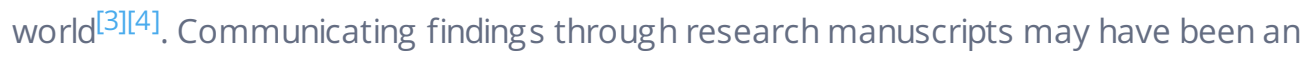
astounding leap forward when it first arose in the 17th century, but now clearly fails to 
meet science's own exacting standards. A paper alone is, simply put, too often inadequate to enable others to reproduce, replicate, remix, and re-use reported results in the ways needed to tackle the complexity of the human nervous system. Doing so requires, at least, open access to and use of the data, research methods, materials, and software underlying the reported results.

What The Neuro came to realize, in sum, is that the way neuroscientists work together needs to once again evolve if progress in understanding the human nervous system and treating neurological diseases is to be more than piecemeal and unreliable. Just as the founding of The Neuro created a new species of institute eng ag ed in neuroscience research, and sharing results through papers and journals was a leap in scientific communication, the time has come for a new evolutionary epoch in neuroscience. History will come to know that epoch as the age of open neuroscience.

\section{Intellectual Property and Open Neuroscience}

The connection between open science and intellectual property often seems daunting in its complexity, but taking a step back can be reduced to a relatively simple set of ideas. Open science requires that the sharing and subsequent use of all information, tools, and knowledge relevant to an experimental result be as frictionless as possible; that, in other words, others are able to access and use everything that went into and came out of an experiment with a minimum of restrictions. Intellectual property exists precisely to restrict access to or use of information and knowledge. Patents restrict how knowledge is applied to produce a result; copyright restricts how knowledge and information are copied and disseminated; technological protection measures coupled with anti-circumvention laws (aka DRM) and trade secret laws restrict access to information; and trademarks and certification marks restrict how information about an entity's identity can be used.

There are limits and restrictions on the breadth of various IP instruments - for example the inability to patent abstract knowledge, equations, and naturally occurring phenomena; or the fact that copyright does not cover facts but how they are creatively expressed - but the above description will serve as a useful and accurate heuristic for understanding how IP impacts knowledge generated through research. As a final note here, I am primarily addressing IP relevant to Canada and the United States, and so will not be addressing things like database rights, though the concerns herein apply to many non-North-American species of IP as well. 
In some cases, such as patents and copyright, intellectual property rights held by academic researchers or institutions must be either eliminated or heavily modified to be compatible with open science. The necessary application of an attribution-only open licence to copyrighted articles to make them truly open access is emblematic here; without such an open license publications cannot be reused in the multitude of ways open science needs (e.g. free text-mining and creating translations). While it is possible to have patenting practices completely compatible with open science by, for example, obtaining a patent and dedicating it to the public domain, doing so is highly inefficient when a novelty killing public disclosure can accomplish the same thing at essentially no cost.

Trade secrets too pose a problem because their very existence is premised on the absence of public access to information. Maintaining such secrecy is anathema to true open science. Technological protection measures, combined with laws that make it illegal to circumvent them, are also in many ways inimical to open science, though, as explained below, can serve a useful purpose if used judiciously. Trademarks and certification marks, on the other hand, pose little difficulty to open science and, in fact, may be key drivers of the future of open science based innovation by allowing groups to reliably label something as deriving from a particular institute or company, or that it meets certain open standards.

To state it baldly, the presence of most forms of IP coupled with enforcement activities aimed at preventing others from accessing and using knowledge hampers the most effective dissemination and use that knowledge. While it is possible to have IP and simply not engage in enforcement activities, doing so injects unnecessary uncertainty - it is always possible that the IP will be sold or exclusively licensed to an entity that will enforce it or that the rights holder may simply change their mind - and in the case of patents leads to high costs for essentially no gain. When the results so restricted are the basic building blocks of further work the cost is large and, as the history of university technology transfer and the research publishing industry has demonstrated, the benefits few and unevenly distributed. In view of these issues The Neuro adopted, through its Open Science Principles, a policy under which it will not claim restrictive IP rights over any of its research outputs nor will it support its researchers in doing so.

\section{Standing on the Open Shoulders of Giants}

Thankfully, The Neuro did not have to start from a blank slate when designing its policy approach to IP. When it comes to patents and trade secrets, The Neuro could adapt the approach taken by the Human Genome Project ("HGP"). Under the Bermuda Rules ${ }^{[5]}$, 
those eng aged in decoding the human genome agreed not to patent any DNA sequences and to publicly release those sequences within 24 hours. This approach was necessary if the required level of collaboration was to be achieved; bickering over ownership and multiple labs racing to sequence the same potentially high value target would simply not get the job done.

The connection between the HGP and the current effort to solve the neural code (or "neural connectome") is entirely apposite. Both are collective journeys of basic scientific discovery tackling a problem much too large for any single lab, institute, or even country to take on itself. The Structural Genomics Consortium, eng aged in large part in decoding the humanproteome, has long followed its own open science philosophy. Each of these efforts is tied together by their ambition to solve a different facet of complex human biology, and each has recognized the importance of coordination and eliminating IPbased barriers to collaboration, dissemination, and reuse.

Advances in the diagnosis and treatment of human maladies is based fundamentally in our basic understanding of biology, which, given the complexity of biological systems, in turn depends on the collaboration and open sharing. Previous research practices ensiled and uncoordinated research, sharing research results solely through (mostly paywalled) manuscripts that lack details crucial to replication and reproduction, and patenting basic discoveries - are clearly not working.

In the neuroscience context, this conclusion is amply demonstrated by the continued reliance on treatments discovered in the 1950s for Parkinson's disease ${ }^{[6]}$ and the high failure rate of new potential treatments for Alzheimer's Disease ${ }^{[7][8][9]}$, Huntington's Disease ${ }^{[10]}$, and $A L^{[11]}$. We need better models, theories of disease mechanisms, and biomarkers if we are to have a real impact on the suffering caused by neurological disorders. The only real hope of gaining these fundamental insights when faced with a problem as complex as the human nervous system is through an open, maximally IP-free approach.

\section{The Neuro's Position: No Restrictive Intellectual Property}

The Neuro's approach to intellectual property, implicit throughout its Principles but found explicitly in Principle 4, is one they have called "no restrictive intellectual property." It means, in short, that The Neuro's researchers should not apply for or enforce any form of IP over research outputs unless doing so is to protect the interests of research participants or contribute to the vitality of the scientific research ecosystem. 
This approach is in many ways analogous to the open

source and open knowledge definitions, though adapted to a context where (1) some shared resources - like individually identifiable research participant data - can include sensitive information that can and should be protected, and (2) an existing academic incentive structure acts to build a strong scientific ecosystem. By adopting a no restrictive-IP position The Neuro is bring ing into practice the now central idea in open science of "as open as possible, as closed as necessary"[12][13] while further ensuring that, where necessary, IP restrictions can be used to aid rather than hinder open science.

\subsection{Non-Restrictive IP Rights}

It will be useful to explain in more detail what is meant by IP being "non-restrictive". The idea breaks down into two general categories.

\subsubsection{Protecting the Interests of Research Participants}

The first and most important category relates to circumstances where a shared resource involves concerns around research ethics and the interests of research participants. This is most clearly the case with individually identifiable data. If, for example, MRI data is bundled with clinical information that could be used to identify a participant, it may be appropriate to include some technological protection measure or contractual restriction such that that identifying information can only be accessed with a password, within a secure system, by registered users, or after evaluation of a data access request.

The tiered access model developed for The Neuro's C-BIG Repository is a good example of how these ideas are being put into practice. Data which pose little risk to participants' interests (like metadata) are openly accessible, those posing some risk require registration and agreement to a terms of use and a set of community norms, while access to individually identifiable data and samples is controlled by C-BIG's T issue and Data Access Committee.

Far from hindering open science, these kinds of restrictions incorporate the idea of responsibility for the interests of research participants and patients into The Neuro's conception of openness.

\subsubsection{Credit Sharing, Resource Linking, and Use Tracking}

The second category has to do with IP-based restrictions designed to ensure creditsharing, resource linking, and tracking downstream use. Each of these restrictions is 
accepted because they align with the core values of science and its unique incentive structure. As a large bolus of literature - starting with Merton's norms of science ${ }^{[14]}$ and perhaps explained best in economic terms by Paul David ${ }^{[15]}$ - has recognized, the research ecosystem has its own unique set of norms and incentive structures that motivate discovery. These norms and incentives, however, are not those of wealth maximization, property, and economic transactions. They are instead grounded in collective ownership of the fruits of intellectual labour, universal validity, organized skepticism, and disinterested experimentation (for norms) and reputation within your field, career advancement, the joy and challenge of discovery, and contributing to the store of public knowledge (for incentives).

\subsubsection{Credit Sharing}

One example of a non-restrictive approach to IP in the copyright context are open licenses. These licenses eliminate most restrictions related to copyright except those requiring giving proper credit ("attribution") to the creator, for example by applying a Creative Commons Attribution License to scholarly publications. Such restrictions do not significantly interfere with downstream use and, in fact, align with existing academic incentives where recognition and reputation are key motivators.

One must be careful, of course, because the impacts of different restrictions can vary between research outputs. While an attribution license on a publication may pose little problem, the same may not be true for certain types of datasets because of the difficulty following them could pose for efficient combination (or combination of combinations) of many datasets. Such difficulties regularly arise as open science evolves and should be attended to carefully.

\subsubsection{Resource Linking and Use Tracking}

Linking related and derived research outputs, or tracking downstream use of research outputs, is important to maintain provenance, create an easily navigable research space, and establish trust between researchers and participants. Doing so can be accomplished, for example, by including contractual restrictions that oblige those who use a shared resource to associate downstream research and commercial outputs with persistent identifiers, like Digital Object Identifiers or Research Resource Identifiers. These identifiers, being persistent and machine readable, can then be easily tracked as a resource makes its way through levels of downstream discoveries and innovations.

The above uses of IP rights and contractual restrictions help align open science practices 
with academic incentives, create a more navigable research space, and maintain participant-researcher trust, all of which contributes to the sustainability of open science while applying a minimum of legal restrictions. They also speak directly to some of the concerns expressed by those in The Neuro's research community during its buy-in process $^{[16]}$.

\section{Doing our Research on IP and Innovation}

The Neuro's decision to adopt an approach that avoids restrictive intellectual property was informed by more than the historical and theoretical considerations discussed so far. It also considered the current relationship between IP and university research generally as well as the innovation history of The Neuro.

The growing ferment around the necessity of applying open licenses to publications and datasets have been discussed extensively within the open science literature. The arguments within that corpus are powerfully made and, in The Neuro's view, decisive. As such, I restrict my assessment below to patenting practices because patents represent an equally important (though less widely accepted) area where IP is having undesirable results.

\subsection{Negative Impacts of Patents on University Research}

There are many troubling trends in university patenting practices. Universities tend to conduct basic research to produce knowledge that enables further downstream research, provides the knowledge taught to students, and lays strong common base upon which private commercial development thrives. Such basic discovery and knowledge dissemination is, indeed, one of the primary social and economic functions noncommercial science performs.

When these basic knowledge outputs are subject to the restrictions imposed by patents because of potential (and in the vast majority of cases unrealized ${ }^{[17][18]}$ ) commercial potential, they pose at worst a serious risk of hindering downstream research and future commercial development ${ }^{[19]}$ and at best contribute little to downstream innovation ${ }^{[20]}$ and the public good ${ }^{[21]}$. In a world with ubiquitous interconnected information technology, and the ease such technology brings to sharing information, the best way of making sure important basic knowledge gets to where it needs to go is to make it FAIR and get out of the way.

\subsection{Contributing to Thickets}


The all too likely result of increased university patenting practices ${ }^{[22]}$ is simply a contribution to a growing patent thicket, like that routinely commented on in nanotechnology ${ }^{[23]}$. Non-commercial research is, unfortunately, not legally exempt from the resulting tangle of patent rights ${ }^{[24]}$, meaning that both private and academic researchers must overcome a prolix nest of IP rights and monopolistic prices, or waste time designing around the thicket.

If, as is so often the case, researchers lack sufficient time or financial resources to obtain a license or buy equipment with a high monopoly-dictated price, they may be forced to abandon research directions all together. Alternatively, they may need to resort to extralegal measures like pirating research software or obtaining reagents directly from colleagues without institutional permission to do so, risking infringement claims and institutional disciplinary actions.

\subsection{Perverse Incentives}

The prevalence of patenting at universities has negative impacts throughout the institutional hierarchy. At the level of the researcher, the possibility of a patent over a research output injects a direct financial incentive into what is supposed to be unbiased discovery. Doing so can lead to counterproductive practices such as not sharing the tools others need to replicate and build on published results[25][26][27]. It can also lead to significant publication delays as researchers attempt to avoid novelty killing public disclosures which would make their research outputs unpatentable.

Almost certainly the biggest cost, however, is not due to researcher secrecy or egos, but to institutionally caused delays in sharing resources due the ongoing realignment of institutional values towards commercialization through IP. The (very small) possibility of a windfall through successful licensing or creation of spin-off companies has slowly introduced complex and unnecessarily restrictive IP clauses in material transfer agreements and research collaboration agreements. These IP clauses routinely pose the greatest negotiation sticking-points, and require the most negotiation time, both for transfers ${ }^{[28]}$ and for industry collaboration contracts. Eliminating such clauses gives up little and would have a multiplicatively beneficial effect to collaboration.

The resulting delay interferes with researchers' ability to rapidly share their tools and effectively collaborate ${ }^{[29]}$. Despite the fact that such interference in each individual case may be small - though still often on the order of weeks or months - the cumulative effect represents years of waste. What is worse, the majority of academic researchers have 
little interest in obtaining patents and yet are hampered in collaborative efforts by having to sign contracts weighed down by clauses designed to cater to the minority that do. Such practices are emblematic of what happens when direct economic incentives begin to infect and displace existing academic research norms and incentives. From The Neuro's experience, the adoption of an open transfer agreement by the C-BIG Repository has dropped transfer times for participant samples and cell lines from months to weeks or days.

\subsection{Patent Litigation and Trolls}

With the increasing incidence of patent litigation generally ${ }^{[30]}$, including by universities ${ }^{[31]}$, concern around real and potential negative impacts of patents on academic research mounts. A good example of the situation The Neuro wants to avoid is the current patent battle over CRISPR ${ }^{[32]}$. Forcing the transfer of perhaps the greatest tool genetic science has ever known through the bottlenecks of IP-based considerations will not help science advance. The historical cases of the Oncomouse ${ }^{[33]}$, involvement of universities in cases defending patents over genes ${ }^{[34]}$, and the ongoing dispute involving a CAR-T therapy ${ }^{[35]}$ also present significant cause for concern.

It is also extremely troubling that university patent practices can either feed patent trolls ${ }^{[36]}$ (also see this 2016 dataset of university patents owned by Intellectual Ventures) or, worse, cause universities to act like them ${ }^{[37]}$. Assertion of patent rights is big business with the potential for substantial returns, but only at the cost of blocking the fluidity of ideas that is the lifeblood of science.

\subsection{Restrictive IP and the Threat to Open Science}

Finally, restrictive IP and the enforcement thereof presents a particular danger for open science. In a world where every aspect of research is digitally shared, interlinked, and machine-readable, the cost of finding potentially infringing research activities and interfering with them through cease-and-desist letters, demands for settlement or licences, and similar rent seeking behaviours decreases.

To put it simply, the more open you are the cheaper it will be to use IP rights to interfere with research regardless of whether it is actually infringing any rights. The tacit but notlegally-enforceable immunity from patent litigation most academic researchers and universities have so far enjoyed may well evaporate as the cost-benefit calculation changes and the generation of profit through patent enforcement activities is normalized. 


\subsection{Conclusion about University Patenting}

To be clear, The Neuro's approach is not "anti-patent" across the board. Commercial entities who use the public knowledge generated by academic institutions to create their own private innovations may be fully justified in applying for patents over those innovations in order to overcome the substantial financial barriers between an innovation and the people it could help - the prime example being the hundreds of millions of dollars often required to bring a new pharmaceutical product through clinical trials.

A patent over a new, privately discovered delivery mechanism for an openly shared molecule with therapeutic potential, a chemical tweak to that molecule, or a new method of manufacturing that molecule, are prime examples of such downstream and patentable innovations. The literature around patent evergreening ${ }^{[38][39]}$ indicates that private firms are in fact marvelously suited to produce and protect just such innovations.

The Neuro is, instead, against patents over the research outputs produced by primarily publicly funded institutions conducting basic research to produce knowledge that is, in most cases, far from direct commercial application and of immense use in downstream research. By forgoing patents The Neuro increases collaboration and moves the monopoly downstream, thereby increasing the wealth of basic knowledge and the quality and diversity of commercial innovations, as well as spurring the competition that drives down prices. This stance is not limited to the outputs of basic research. The same logic holds true for discoveries emerging from academic institutions that do appear to have near-term commercial application; openly sharing them provides a common base from which market-competitiveness can work its price-reducing magic.

\section{The History of Innovation at The Neuro}

In late 2019 The Neuro gained even more confidence in its position on IP by looking at the innovation activity coming out of The Neuro. Before joining The Neuro, and during my time as their Open Science Alliance Officer, looked at both the last 20 years of patent based technology transfer as well and the spin-off companies that have emerged from The Neuro.

\subsection{Patents on Neuro Research Outputs Filed Through McGill}

To assess the innovation history here at The Neuro I obtained technology transfer data on reports of invention ("ROI"), patent applications, granted patents, and licensing agreements generated by Neuro faculty as of September $2019(\mathrm{~N}=84)$ form McGill 
Innovation and Partnerships (McGill's Technology Transfer Office).

\section{A Note on the Data}

I limited the analysis a priorito ROIs reported between January 2000 and September 2019 for two reasons. The first is in order to capture the history of those patents that would most likely not have reached their 20-year expiry by the time of analysis. The second is that the farther back in time one goes the more likely it is that McGill may have filed a patent based on the work of a faculty member who had left prior to 2019 and was, therefor, not included in the September 2019 cohort. I believe the resulting dataset gives a reasonably accurate, if not perfect, portrayal of patent-based innovation activities despite these limitations.

Unfortunately I am only able to make a subset of this data publicly available in the supplementary materials due to much of it being confidential information. The supplementary csv file "Granted Patents With Neuro Inventors Filed by McGill" includes the data on granted and publicly disclosed patents. Some fields have been removed for to preserve confidential information ( $\mathrm{ROI}$ disclosure date, invention title, and list of inventors). Information in remaining fields are as received from McGill Innovation and Partnerships. The only added field is where I have included a patents.google.com or a link from the relevant jurisdictional patent office accompanying each entry.

\section{Summary of Results}

The summary of my investigations is that, between 2000 and September 2019, 99 ROls were filed, of which just over half came from just 5 faculty members. Despite a subset of these 99 ROls leading to 152 patent applications of various kinds, only 23 were ever given official intellectual property numbers, and of these only details of 20 can be found on the public internet (see supplementary data). Of the 23 granted applications, 10 were abandoned, leaving 13 currently active patents relating to 4 ROls.

I then looked more deeply into the currently active patents: Two were for an ROI concerning an antisense oligonucleotide with potential utility in treating cancer, three related to two ROIs regarding software for analyzing brain morphology, and the remaining eight were for a single $\mathrm{ROI}$ relating to a gene associated with epilepsy.

\subsubsection{Commercialization of Patents Over Neuro Research}

The antisense oligonucleotide patents were subject to an exclusive license agreement that was terminated before leading to a product. The three software patents constitute 
a portion of the assets owned by a Neuro spin-off that has been running for approximately 15 years but which, according to discussions with the founder, has had to divert much of its revenue into IP related legal and maintenance fees and, because of an IP inventorship dispute, is now unable to sell the company.

The eight gene related patents, applied for many years ago by The Neuro's Director Dr. Guy Rouleau and some of his colleagues, consist of 1 Australian patent licensed to Bionomics Ltd, 1 Canadian patent, 1 Japanese patent, and 5 US patents based on continuation or divisional applications to the USPTO - the multiple applications likely due to a scramble to recover patentable subject matter in the wake of the Myriad decision ${ }^{[40]}$ . None of these patents have led to a successful diagnostic or treatment product. As noted in Dr. Rouleau's recent article in Cell[ ${ }^{[1]}$, this failure to produce any useful product is a significant part of his motivation in transitioning The Neuro to an open science model.

\subsection{Innovation Activities through Neuro Researcher-Entrepreneurial}

\section{Activities and Spin-Offs}

During The Neuro's buy-in process in 2016 Dr. Viviane Poupon, COO of the Tanenbaum Open Science Institute at The Neuro, looked into innovation activities through Neuro researcher initiated companies. She collected data on these companies by eng ag ing with Neuro faculty through email and in person to report companies and spin-offs. In December 2019 I extended her results by searching eng aging with faculty, searching Google and Linkedln based on the names of faculty members, following up on entries in the technology transfer data that indicated that McGill had transferred the rights to commercialize an innovation back to the inventor.

These efforts resulted in information on 17 companies (see company names, founders, and patent category in supplementary data file "Spin-off Companies, Founders, and Patent Status"). The main factor of interest was whether any of these companies relied on patents over research outputs generated within The Neuro. To find out, I spoke with company founders and searched Google Patents and Lens.org using faculty and company names.

Only the software company discussed above relied on a patent over a Neuro research output. It should be noted here that, because of the primacy of founder expertize in using the software, had the company been founded less than a decade later when open source business models were becoming normalized it could likely have been run on an open source software-as-a-service basis, thereby avoiding the IP-issues that have 
plagued it. One company relied on a patent over a research output generated at another institution and refined through collaboration with a Neuro researcher. Ten companies relied on patents covering innovations generated outside of The Neuro, while five didn't rely on patents at all.

\subsection{Limitations of Analysis}

Multiple confounding factors make the above analysis less than perfect. The amount of information I can share about the agreements patents led to is, unfortunately, limited due to it being confidential business information as well as the limited nature of the information in the received data set. The data I received, for example, included information about whether a patent was subject to a licence, but nothing concerning the licencee, royaltees or bulk payments received by McGill, nor whether the licence led to a successful product. Where possible I attempted to find this information by searching google, Linkedln, Lens.org, and discussing the patent in question with the researcherinventor. These limitations puts $\mathrm{Me}$ in a bit of an awkward position as a member of an institute that prizes reproducible analysis and data sharing. My hope is that it emphasizes yet again the difficulties introduced when universities eng age in secretive business practices.

There are further limitations to my analysis, including those related self-reporting, a lack of information on ROIs by researchers who had left The Neuro prior to 2019, and the limited amount of publicly available information concerning how any given patent leads to a commercial product or service. Further, the technology transfer data didn't include information on research contracts where all resulting IP is wholly and immediately assigned to an industrial sponsor.

\subsection{Conclusion Based on The Neuro's Commercialization Activities}

Despite the above limitations, and in view of the massive potential of IP-free open sharing, the results reinforced the idea that eschewing patents over research outputs would have a negligible, if any, negative impact on the development of diagnostics and treatments or on researcher-entrepreneurial activities. Ultimately, attempts to patent Neuro research outputs led to very little and, because a patent can often cost many tens of thousands of dollars before it is granted and tens of thousands more to maintain throughout its 20-year life (even without taking into account the millions of dollars it takes to defend a patent in litigation), these patents almost certainly cost McGill more taxpayer dollars than they ever had a chance of receiving in royalties or patent buy-outs. 


\section{The Impossibility of Opening McGill-IP for the COVID-19 Pandemic}

There is a growing literature on the importance of open science to combatting the COVID-19 pandemic, including the importance of removing IP-related barriers to the sharing of research resources and the dissemination of potential treatments ${ }^{[42]}$. I have not commented significantly on the pandemic so far because it is just one of the many clear examples of where an open approach is required - if a particularly poignant and timely one.

One example, however, deserves mentioning. The Neuro was one of the original supporters of the Open COVID Pledge, a pledge by IP holders to release their IP openly for the purposes of ending the pandemic. Since it was first announced notable companies - including Amazon, Facebook, Intel, and IBM - have taken the pledge. The Neuro leadership approached the McGill Administration and asked them to consider having McGill become a pledgor.

The response was that they were unable to. Not, please note, that they were unwilling, but that they were quite literally unable to take the pledge, the main reason being that the IP policies and contractual practices engaged in by McGill fully transfer all meaningful rights outside the institution. In other words, the IP generated over discoveries made at McGill is so wholly owned by individual inventors and corporate sponsors that they do not have the latitude to release it for others to openly use, even in the context of a global pandemic. McGill's position in this regard is in no way unique in the Canadian context and, as such, speaks to a much larger problem.

\section{Innovation Activities Using Open Science Compatible IP Practices}

The Neuro has gained yet more confidence in its position by keeping close track of the emerging possibilities for commercialization activities that do not rely on restrictive IP protection. This paper is not the place to go into the full discussion these non-IP-based innovation approaches deserve, but it is worth saying a few words.

Many open science compatible models work by applying either the logic of open-source software business models, non-profits, or open biobanks to provide products and services aimed at improving science itself. Companies and non-profits are emerging to enable data sharing (e.g. OSF), develop research software (e.g. Open Science Tools), design and sell research equipment (e.g. Open Ephys, OpenT rons, OpenBCl), and 
disseminate materials (e.g. Addgene) at a fraction of the cost of proprietary models. These efforts are largely driven by members of the scientific community itself and represent a slow but seismic shift away from companies eng aged in linear, restrictive, and secretive development and towards a model based on distributed, facilitated collaboration between members of the relevant scientific community.

Other possibilities, including tool and technique vetting services (e.g. Y-Char-OS), synergy between open science and artificial intelligence ${ }^{[43]}$, open science drug development ${ }^{[44]}$, and open source medical software (e.g. Meningioma.app) represent new ways of impacting scientific research and the lives of patients without relying on restrictive IP. A particularly interesting aspect of these efforts are their funding models, which often rely on joint investment by private companies, governments, academic institutions, and philanthropic organizations. The Neuro's Early Drug Discovery Unit, an open platform for testing potentially therapeutic compounds in cell lines derived from patients, uses just this kind of model.

Such mixed funding models effectively distribute risk, reduce individual-party costs, and hold the hope of pushing forward development of treatments and diagnostics in areas for which existing private-market models systematically fail - including neurological disorders, rare diseases, neglected tropical diseases, antibiotics, and, of particular importance now, vaccines.

The great strength of all of the above efforts is the ability to capitalize on or facilitate global collaboration and rapid, iterative development of products and services. By delivering value to user-collaborators and allowing rapidly iterative modification of products and services without relying on IP they can avoid the often weighty costs and heavy restrictions associated with obtaining and enforcing IP all while contributing to the well of public knowledge (not to mention remaining financially sustainable).

\section{Conclusion: Trying, Testing, and Sharing}

The Neuro is confident that the approach is has developed is - given its institutional context, values, and history - the best way to encourage basic science, the commercial development of diagnostics and treatments, and neuro-based innovation generally. It is always possible, however, that the approach will need to be changed or refined. The Neuro is, after all, an open science experiment itself, and will have to adapt based as the global open research and open innovation ecosystems develop. 
As with any experiment, the most important thing is to decide what constitutes success and ways of measuring it. For The Neuro, success is measured in terms of improved basic research and the contribution of that research to bettering the lives of patients. Some early indicators are promising, including significantly reduced material transfer times using C-BIG's Open Transfer Agreement, increasing industry interest and investment in Neuro open platforms and projects, and ongoing collaborations with pharmaceutical companies to develop industry grade assays for drug discovery through The Neuro's Early Drug Discovery Unit.

The only way The Neuro can know is to try out its approach, test if it is working in the best way it can, and share what it learns. This paper is just one early element of that sharing. The Neuro encourages other institutes to commit to open science, and thereby to the health of the scientific discovery ecosystem itself, adopt their own open science compatible IP approach, and share what they learn in turn.

Acknowledgments: I would like to acknowledge the helpful feedback and comments received on this draft from Lucie Guibault (Schulich School of Law) and Adrian Thorogood (Centre for Genomics and Policy, Mc Gill University).

\section{References}

1. ^ Roberto Lent, Frederico A. C. Azevedo, Carlos H. Andrade-Moraes, Ana V. O. Pinto. (2011). How many neurons do you have? Some dogmas of quantitative neuroscience under revision. doi:10.1111/j.1460-9568.2011.07923.x.

2. ` Z. Josh Huang, Liqun Luo. (2015). It takes the world to understand the brain. Science, vol. 350 (6256), 42-44. doi:10.1126/science.aad4120.

3. ^ Monya Baker. (2016). 1,500 scientists lift the lid on reproducibility. Nature, vol. 533 (7604), 452-454. doi:10.1038/533452a.

4. ^ Padraig Gleeson, Andrew P. Davison, R. Angus Silver, Giorgio A. Ascoli. (2017). A Commitment to Open Source in Neuroscience. Neuron, vol. 96 (5), 964-965. doi:10.1016/j.neuron.2017.10.013.

5. ^ Eliot Marshall. (2001). Bermuda Rules: Community Spirit, With Teeth. Science, vol. 291 (5507), 1192-1192. doi:10.1126/science.291.5507.1192.

6. ^Atbin Djamshidian, Werner Poewe. (2016). Apomorphine and levodopa in Parkinson's disease: Two revolutionary drugs from the 1950's. Parkinsonism \& Related Disorders, vol. 33, S9-S12. doi:10.1016/j.parkreldis.2016.12.004.

7. ^ Dev Mehta, Robert Jackson, Gaurav Paul, Jiong Shi, Marwan Sabbagh. (2017). Why do 
trials for Alzheimer's disease drugs keep failing? A discontinued drug perspective for 2010-2015. Expert Opinion on Investigational Drugs, vol. 26 (6), 735-739. doi:10.1080/13543784.2017.1323868.

8. ^ Hamid Reza Amanatkar, Bill Papagiannopoulos, George Thomas Grossberg. (2016). Analysis of recent failures of disease modifying therapies in Alzheimer's disease suggesting a new methodology for future studies. Expert Review of Neurotherapeutics, vol. 17 (1), 7-16. doi:10.1080/14737175.2016.1194203.

9. ^ Brent P. Forester, Regan E. Patrick, David G. Harper. (2020). Setbacks and Opportunities in Disease-Modifying Therapies in Alzheimer Disease.JAMA Psychiatry, vol. 77 (1), 7. doi:10.1001/jamapsychiatry.2019.2332.

10. ^André M. Travessa, Filipe B. Rodrigues, Tiago A. Mestre, Joaquim J. Ferreira. (2017). Fifteen Years of Clinical Trials in Huntington's Disease: A Very Low Clinical Drug Development Success Rate. JHD, vol. 6(2), 157-163. doi:10.3233/jhd-170245.

11. ^ Dmitry Petrov, Colin Mansfield, Alain Moussy, Olivier Hermine. (2017). ALS Clinical Trials Review: 20 Years of Failure. Are We Any Closer to Registering a New Treatment?. Front. Aging Neurosci, vol. 9. doi:10.3389/fnagi.2017.00068.

12. ^Annalisa Landi, Mark Thompson, Viviana Giannuzzi, Fedele Bonifazi, Ignasi Labastida, Luiz Olavo Bonino da Silva Santos. (2020). The "A" of FAIR - As Open as Possible, as Closed as Necessary. Data Intelligence, vol. 2 (1-2), 47-55. doi:10.1162/dint_a_00027.

13. ^ European Research Council. (2020). European Research Council. Horizon 2020 Online Manual. European Commission Website.

14. ^ Robert K. Merton. (1973). The Sociology of Science. University of Chicago Press.

15. ^ Paul A. David. (2003). The Economic Logic of "open Science" and the Balance Between Private Property Rights and the Public Domain in Scientific Data and Information.

16. ^ Poupon, V., Seyller, A., Edwards, A., Gold, R., \& Rouleau, G.. (2020). Open Science at the Montreal Neurological Institute and Hospital: the buy-in process. Gates Open Research.

17. ^ H. Bulut, G. Moschini. (2009). US universities' net returns from patenting and licensing: a quantile regression analysis. Economics of Innovation and New Technology, vol. 18 (2), 123-137. doi:10.1080/10438590701709025.

18. ^ Richard Gold. (2019). Should Universities Get Out of the Patent Business?. CIGl Online.

19. ^ Heidi L. Williams. (2013). Intellectual Property Rights and Innovation: Evidence from the Human Genome. Journal of Political Economy, vol. 121 (1), 1-27. doi:10.1086/669706.

20. ^ Bhaven Sampat, Heidi L. Williams. (2019). How Do Patents Affect Follow-On Innovation? Evidence from the Human Genome. American Economic Review, vol. 109 
(1), 203-236. doi:10.1257/aer.20151398.

21. ` Ouellette, Lisa Larrimore and Weires, Rebecca. (2020). University Patenting: Is Private Law Serving Public Values?. Michigan State Law Review, vol. 2019.

22. ^ Christian O. Fisch, Tobias M. Hassel, Philipp G. Sandner, Joern H. Block. (2014). University patenting: a comparison of 300 leading universities worldwide. J Technol Transf, vol. 40 (2), 318-345. doi:10.1007/s10961-014-9355-X.

23. `Joshua M. Pearce. (2012). Make nanotechnology research open-source. Nature, vol. 491 (7425), 519-521. doi:10.1038/491519a.

24. ^A. A. Russo, J. Johnson. (2014). Research Use Exemptions to Patent Infringement for Drug Discovery and Development in the United States. Cold Spring Harbor Perspectives in Medicine, vol. 5 (2), a020933-a020933. doi:10.1101/cshperspect.a020933.

25. ^John P. Walsh, Wesley M. Cohen, Charlene Cho. (2007). Where excludability matters: Material versus intellectual property in academic biomedical research. Research Policy, vol. 36 (8), 1184-1203. doi:10.1016/j.respol.2007.04.006.

26. ^ David Blumenthal. (1997). Withholding Research Results in Academic Life Science. JAMA, vol. 277 (15), 1224. doi:10.1001/jama.1997.03540390054035.

27. ^ E. Richard Gold, Warren Kaplan, James Orbinski, Sarah Harland-Logan, Sevil NMarandi. (2010). Are Patents Impeding Medical Care and Innovation? PLoS Med, vol. 7 (1), e1000208. doi:10.1371/journal.pmed.1000208.

28. ^AUTM. (2011). 2011 Material Transfer Agreement Survey Report.

29. ^Zhen Lei, Rakhi Juneja, Brian D Wright. (2009). Patents versus patenting: implications of intellectual property protection for biological research. Nat Biotechnol, vol. 27 (1), 36-40. doi:10.1038/nbt0109-36.

30. ^James E. Bessen, MichaelJ. Meurer. (2005). The Patent Litigation Explosion. SSRN Journal. doi:10.2139/ssrn.831685.

31. ^Rooksby, J.. (2015). When Tigers Bare Teeth: A Qualitative Study on University Patent Enforcement. Akron Law Review, vol. 46.

32. ' Jacob S. Sherkow. (2016). CRISPR: Pursuit of profit poisons collaboration. Nature, vol. 532 (7598), 172-173. doi:10.1038/532172a.

33. ^ Fiona Murray. (2010). The Oncomouse That Roared: Hybrid Exchange Strategies as a Source of Distinction at the Boundary of Overlapping Institutions. American Journal of Sociology, vol. 116 (2), 341-388. doi:10.1086/653599.

34. ^ E Richard Gold, Julia Carbone. (2010). Myriad Genetics: In the eye of the policy storm. Genet Med, vol. 12, S39-S70. doi:10.1097/gim.0b013e3181d72661.

35. ^ Royzman, I. \& Williams, D.. (2020). CAR T-Cell Therapy Takes Off and Brings on Patent Litigation. Bio Law Blog. 
36. ^Heidi Ledford. (2013). Universities struggle to make patents pay. Nature, vol. 501 (7468), 471-472. doi:10.1038/501471a.

37. ^Feldman, R., \& Lemley, M. A.. (2015). Do patent licensing demands mean innovation. lowa Law Review, vol. 101.

38. ^ Reed F. Beall, Jason W. Nickerson, Warren A. Kaplan, Amir Attaran. (2016). Is Patent "Evergreening" Restricting Access to Medicine/Device Combination Products? PLoS ONE, vol. 11 (2), e0148939. doi:10.1371/journal.pone.0148939.

39. `Thomas A Faunce, Joel Lexchin. (2007). 'Linkage' pharmaceutical evergreening in Canada and Australia. Aust N Z Health Policy, vol. 4 (1). doi:10.1186/1743-8462-4-8.

40. ^ R. E. Gold, R. Cook-Deegan, T. Bubela. (2013). AMP v. Myriad: A Surgical Strike on Blockbuster Business Models. Science Translational Medicine, vol. 5 (192), 192ed9192ed9. doi:10.1126/scitrans/med.3006849.

41. ^ Guy Rouleau. (2020). My Journey to Open Science. Cell, vol. 181 (3), 498-502. doi:10.1016/j.cell.2020.03.018.

42. ^ Luca Li Bassi, Lenias Hwenda. (2020). COVID-19: time to plan for prompt universal access to diagnostics and treatments. The Lancet Global Health, vol. 8(6), e756-e757. doi:10.1016/s2214-109x(20)30137-6.

43. `Kuansan Wang. (2019). Opportunities in Open Science With Al. Front. Big Data, vol. 2 . doi:10.3389/fdata.2019.00026.

44. ^ (2006). The Pharmaceutical Revolution: Drug Discovery and Development. doi:10.1201/9781420004236-35. 